\title{
DETERMINATION OF SEX THROUGH GENES IN A MAJOR SEX LOCUS IN DROSOPHILA MELANOGASTER *
}

\author{
JOHN W. GOWEN and SUI-TONG CHAN FUNG \\ Department of Genetics, lowa State College, Ames, lowc, U.S.A.
}

Rcceived 27.ii. 57

Hereditary control of sex had first support when unequal chromosomes were shown to be directly correlated with the sex of an individual or its progeny. Over the years no specific sex loci could be located within these chromosomes, however. Polyploid types within Drosophila showed that the sex chromosomes were not the only factors. Scx determination appeared to rest rather on a balance between the sex chromosomes and the autosomes. In Drosophila the X chromosomes operated by pushing the organism toward the female type, the autosomes pressed toward the male type. The Y chromosome had little effect. Loci for major sex genes utilising the intersex types as test agents were sought but again in no clear-cut instance were they found. In the interim major sex genes appeared through observed mutational types.

Sturtevant (1920, 192I) in D. simulans isolated a gene in the second chromosome which could convert diploid females to intersexuals, and rendered males sterile. Phenotypically these intersexuals were femalelike in that they lacked sex combs, had 7 dorsal abdominal tergites, ovipositor of abnormal form, 2 spermathecæ and lacked the penis. They were male-like in having first genital tergite although abnormal in form, lateral anal plates, claspcrs, black pigmented tip to the abdomen. The gonads were rudimentary. The genc, as was expected since it was recessive, had no effcct on $D$. simulans $\$ melanogaster hybrids.

Lebedeff (1934) in Drosophila virilis, studied a recessive gene in the third chromosome which converted diploid females into intersexuals. These intersexuals were arranged on the basis of their morphology from extreme female type with nearly normal female appearance and reproductive organs (ovary undifferentiated) to male type (undeveloped testis and sperm). Between these types numerous hermaphroditic progeny occurred having imperfect but corresponding male and female organs jointly present.

Dobzhansky and Spassky (194I) in Drosophila pseudoobscura observed 2 progenies containing intersexual individuals. These intersexuals were thought to be duc to a single dominant gene transforming diploid females. They were characterised by two sets of more or less complete genital ducts and external genitalia but only one pair of gonads. One set of ducts and genitalia was almost always more female-like

* Journal Paper No. J-3028 of the Iowa Agricultural Experiment Station, Ames, lowa. Project No. I 187 . This work has received assistance from Contract No. AT (1 I-I) 107 from the Atomic Energy Commission. 
and the other more male-like. Sex combs were present. The distal comb had 2 to 4 and the proximal 4 to 6 teeth, as compared with the normal male number of 4 to 7 on the distal and 6 to 9 on the proximal combs. Body development was more like the female.

Briles established a dominant gene which caused intersexuality in diploid females. Stone located this gene in the second chromosome of Drosophila virilis. Newby (1942) presented an extended study of the embryological sequence in development of the organs of these intersexual types. Externally, these intersexuals have a total of 9 tergites. The first 6 of these tergites were like those in the normal female, and the last 3 were small and irregularly formed. Six sternites were present; the first 5 were normal but the 6 th was malformed. The anal valves were lateral as in the male, but a 3 rd small valve was also present at the ventral side of the anus. Clasper plates of irregular pattern were found ventral to the anus. Below the clasper plates, the vaginal plates were often extruded as a genital knob. This knob occasionally became heavily pigmented. Internally, development ranged from nearly female individuals through the hermaphrodite type containing representative organs of both sexes to individuals almost wholly male. In brief, from these intersexuals, Newby concluded that " intersexuality expresses itself as a response to the developmental pressure of both sexes, not as development in one direction followed by a change" (page I 39).

These cases were for single mutant genes in which there was no sure method of showing that the wild-type gene truly operated on the sex embryology and phenotype.

Gowen in I 940 established a stock carrying the dominant gene in Drosophila melanogaster, $\mathrm{Hr}$, which affects diploid females; producing sterile individuals with complete male secondary reproductive systems associated with their female counterparts. The primary gonads were certainly often ovarian but in rare instances had a crude resemblance to testicular tissue. This gene showed a dosage effect in triploids but no effect on males. Dosage effect in triploids in conjunction with the types found in the diploids showed that both the mutant, dominant gene $\mathrm{Hr}$, and its wild-type counterpart influenced both the embryological and phenotypical sex. In consequence both the $H r$ and $h r^{\text {. }}$ may be regarded as true major sex genes $\left(h r^{+}\right.$is hereafter written as simply +). Sturtevant (I945) established a recessive gene "tra" in D. melanogaster which was also sex limited in effect. When homozygous, the gene transformed diploid females into sterile males. The primary and secondary sex organs of these "males" were so phenotypically like normal males as to be nearly indistinguishable from them. This gene also changed sex in certain of the polyploid types. In recent crosses we have shown that these three genes -, $\mathrm{Hr}$ and $\mathrm{tra}$ behaved as an allelic series in the sense that crosses between them showed distinguishable phenotypes when such differences would be unlikely if the genes were not allelic or pseudo-allelic. Possible 
combinations of these genes in $\mathrm{XY}+2 \mathrm{~A}, \mathrm{XX}+2 \mathrm{~A}$ and $\mathrm{XXX}+3 \mathrm{~A}$ flies resulted in some so distinguishable sex types. The descriptions and implications of these sex types are considered in the rest of this paper. The problem of what happens in intersexes $\mathrm{XX}+3 \mathrm{~A}$, super females $\mathrm{XXX}+2 \mathrm{~A}$ and super males $\mathrm{XY}+3 \mathrm{~A}$ will be discussed at a later date.

\section{MATERIALS AND METHODS}

The gene series is located in the third chromosome of $D$. melanogaster. Crosses to form diploid and triploid combinations of the + and $\mathrm{Hr}$ genes were made several years ago (1942) and were again represented with like results. Sturtevant kindly supplied the tra gene. The 3 genes have been crossed to form all,$+ \mathrm{Hr}$ and $\mathrm{tra}$ combinations possible in diploids and triploids. Where comparable these crosses gave phenotypes which confirmed those described by Sturtevant or ourselves.

\section{EXPERIMENTAL RESULTS}

The descriptions of the different recognisable sex phenotypes are summarised in table $\mathrm{I}$ for the $\mathrm{XY}+2 \mathrm{~A}$ and $\mathrm{XX}+2 \mathrm{~A}$, diploid and $\mathrm{XXX}+3 \mathrm{~A}$ triploid types.

The reproductive systems differentiating males and females in Drosophila are as complex as those in any animal. It is evident that the three genes under study can convert Drosophila from a bisexual species into multisexual phenotypes. The new forms of especial interest may be described and illustrated as follows.

$\mathrm{Hr} /+$ (diploid hermaphrodite). Externally the body size and form of the hermaphrodite flies resembled diploid females. They had sex combs on the basal tarsal segment of each front leg. The comb consisted of 6-8 slender teeth instead of the usual ro or more found in normal males. The anal valves were of male type but were often displaced and asymmetrical in arrangement. Between the anal valves was a pair of abnormal claspers thickly sclerotised and supported by irregular plates. Within the clasper, orange penis parts appeared. Beneath these plates, a heavily-pigmented and sclerotised protuberance was ordinarily found. This knob generally contained the spermatheca and represented the posterior part of the female genitalia. These flies were sterile.

The internal genitalia of the hermaphrodites exhibited great variability. In the array of individuals studied, there was not a single case which showed complete sex reversion to male type. Each specimen consisted of a mixture of either well-developed or rudimentary sexual organs. Some had well-developed ovaries, in others these organs were rudimentary but all flies of this type contained distinct sexual organs of either sex. In most individuals, tiny yellow masses were found to be associated with the gonads or the genital systems, particularly the paragonia. The pigmentation of these tissues resembled the yellow pigment present in the testicular epithelial sheath cells. The male accessory glands, the paragonia, were most commonly to be observed. They were irregular in form, number, 


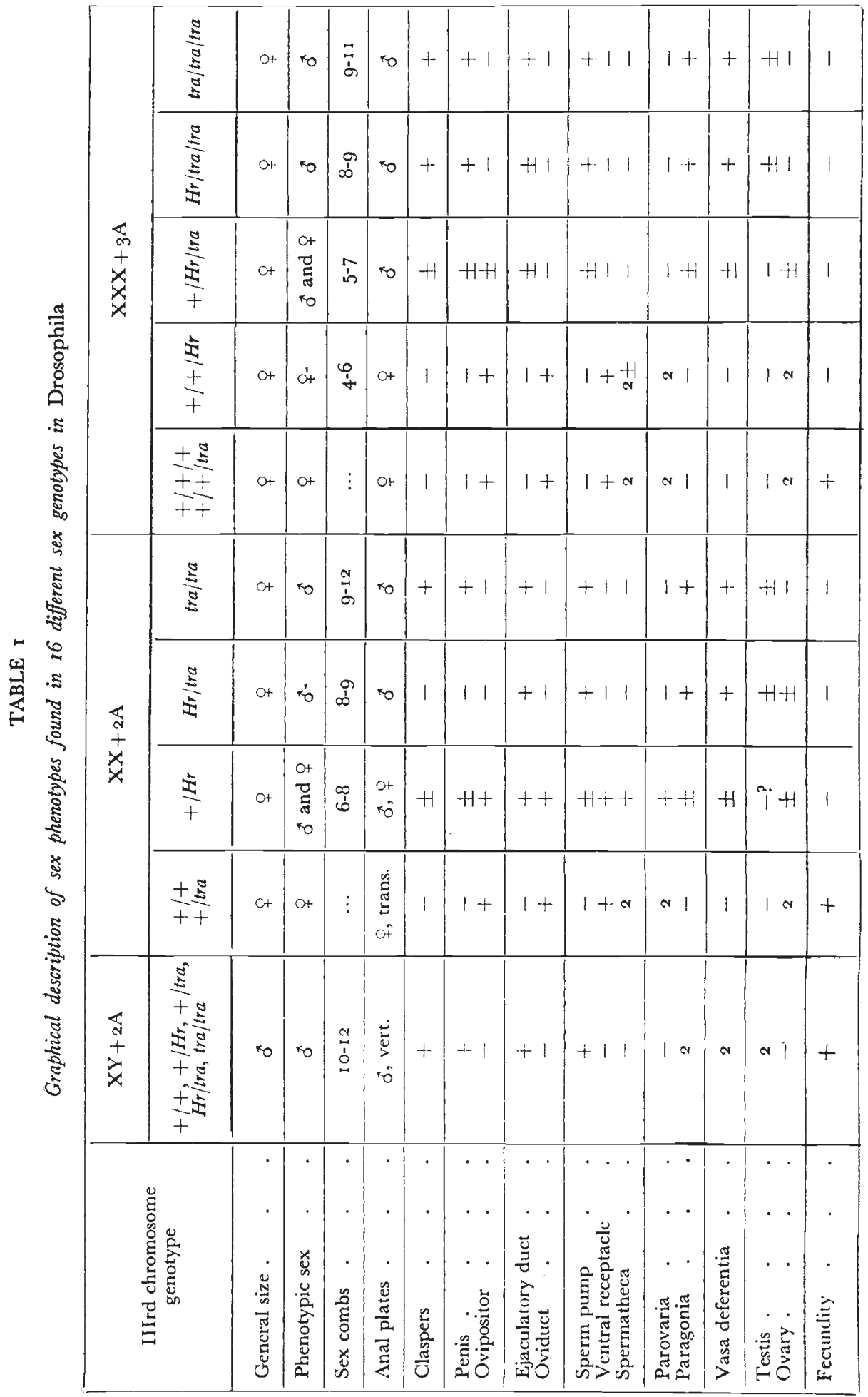


and attachment. The sperm pump was likewise abnormal in shapc. The rod-shaped sclerite at the centre of the pump was generally missing or, if present, poorly developed. Of the female accessory organs, the spermathecæ and ventral receptacle were generally present. Dual duct systems which contained both ejaculatory ducts and oviducts were found in most individuals. Structural differences in these types and the behaviour of the imaginal discs for these organs on transplantation have been extensively studied (Fung and Gowen, I957a, I $957 b)$.

Hr/tra. The body size of these flies resembled that of females. Morphologically, this sex type was clearly distinguishable from the $\mathrm{Hr} /+$ hermaphrodites. Their external genitalia were male-like but appeared retracted, with no visible claspers. On the first tarsal segment of the forelegs, the sex combs consisted of a row of 8-9 teeth.

The internal genitalia were generally composed of male sexual organs. Vasa deferentia and paragonia as well as the ejaculatory ducts and sperm pump were well developed. Gonads generally consisted of rudimentary or under-developed testes. The development of the female genital system seemed to be almost replaced by that of the male.

$\mathrm{Hr} / \mathrm{H} /+$. Externally these flies resembled $+1+1+$ triploid females. They normally had larger bodies, coarser bristles, and larger ommatidia and wing cells than diploid females of $\mathrm{XX}+2 \mathrm{~A},+1+$ genotype. They were distinguished from $+1+1+$ by having sex combs of 4-6 long and slender teeth. The tips of their abdomens were slightly darkened. The internal genitalia were completely female. In spite of the great similarity between these triploids and the normal diploids, they were completely sterile.

$\mathrm{Hr} / \mathrm{tra} /+$. These flies had bodies, ommatidia, and wing cells of larger size than wild diploid females of $\mathrm{XX}+2 \mathrm{~A}$ genotypes. Their external genitalia resembled $\mathrm{Hr} /+$ (diploid hermaphrodites) with rudimentary claspers and sclerotised protuberances. They had sex combs on the forelegs with 5-6 teeth. The internal genitalia were predominantly male with well-developed ejaculatory ducts and paragonia. The gonads consisted of free ovaries or ovary attached to the vasa of the male genital system.

Tra/tra/tra. These individuals had large bodies, ommatidia, and wing cells. External genitalia were identical to normal diploid males. Sex combs consisted of IO-I I teeth. The internal genitalia have a well-developed ejaculatory duct, sperm pump, and accessory gland. The testes were elongated but much smaller than in normal males. These flies mated with females but were completely sterile.

\section{SUMMARY}

This paper presents a summary of sexual types due to the actions and interactions of three major sex genes operating on the normal 
gene background of Drosophila melanogaster. Because of their phenotypic expression in crosses, these genes are assigned to a single major locus for sex determination in the 3 rd chromosome.

Different diploid and polyploid combinations of the genes,$+ \mathrm{Hr}$ and tra have been made for the study of their sex types. Besides the familiar normal males and females, the triploid types of Bridges, the two $\mathrm{Hr}$ types of our stock, and the two male types of Sturtevant, three new distinguishable sex phenotypes have been found. The diploid genotype $\mathrm{Hr} / \mathrm{tra}$ had male-like but retracted genitalia and no visible claspers, sex combs of 8-9 teeth, and internal genitalia largely male. The $\mathrm{Hr} / \mathrm{tra} / \mathrm{tra}$ resembled the $\mathrm{Hr} / \mathrm{tra}$, having sex combs with 8-9 teeth, internal genitalia predominantly male, well-developed duct and accessory organs, and testes elongated slightly but much smaller than those of normal males. The $\mathrm{Hr} / \mathrm{tra} /+$ flies had rudimentary claspers and sex combs of 5-6 teeth. The internal genitalia were developed with ejaculatory duct, paragonia and gonads with free ovaries or ovaries attached to vasa of the male system.

Besides the intersex genotype, $2 \mathrm{X}+3 \mathrm{~A}$, which was little affected by these genes, ten distinguishable sex types were produced by the action or interaction of these genes in the diploid and triploid flies. Dosage interactions in diploids and triploids proved that + of the wild type was a sex gene like the $H r$ and tra. The results show that fundamental sex characters, like other characters, sometimes may be altered by substitution of major sex genes occupying particular loci.

\section{REFERENCES}

DOBZHANSKy, TH., AND SPASSKy, B. 1941. Intersexes in Drosophila pseudo-obscura. Proc. Nat. Acad. Sci., 27, 556-562.

FUNG, s. T. C., AND GOWEN, J. W. I957a. Intersexuality in Drosophila. The developmental effect of a sex-limitcd gene in Drosophila melanogaster. 7. of Exp. Zool. I34, 5I 5-532.

FLNG, S. T. C., AND GOWEN, J. W. 1957b. Pigment-inducing potentialities of testes, ovaries and hermaphroditic $(\mathrm{Hr})$ gonads. F. of Exp. Zool. (In Press.)

GOWEN, J. W. 1942. On the genetic basis for hermaphroditism. Anat. Rec., 84, $45^{8}$. LEBEDEFF, C. A. 1934. A gene for intersexuality in Drosophila virilis. Amer. Nat.; $68,68-69$.

NEWBY, W. W. 1942. A study of intersexes produced by a dominant mutation in Drosophila virilis, Blanco Stock No. 4228: I13-145, University of Texas Publication.

Stlrtevant, A. H. 1920. Intersexes in Drosophila simulans. Science, 5I, 325-327.

stcrtevant, A. H. 1921. Genetic studies on Drosophila simulans. III. Autosomal genes. General discussion. Genetics, 6, I 79-207.

stcrtevant, A. H. 1945. A gene in Drosophila melanogaster that transforms females into males. Genetics, 30, 297-299. 